\title{
AOP3S : A Balanced Approach to Model Distributed Manufacturing Systems
}

\author{
Luiz Marcio Spinosa ${ }^{1}$, Bernard Espinasse ${ }^{2}$ and Eugène \\ Chouraqui $^{2}$
}

${ }^{1}$ G-SIGMA - Intelligent Manufacturing Systems Group, Mechanical Engineering Department of the Federal University of Santa Catarina, Brazil, Tel. (55) 48 3319387, Fax : (55) 48 2341519, E-mail : spinosa@gsigma-grucon.ufsc.br ${ }^{2}$ DIAM / IUSPIM - University of Aix-Marseille III, France, Tel. : (33) 0491056030, Fax : (33) 0491056033, E-mail : (bernard.espinasse,eugene.chouraqui)@iuspim.u-3mrs.fr

\begin{abstract}
In order to improve the competitiveness of current manufacturing enterprises, the European Committee for Standardisation, Technical Committee Advanced Manufacturing Technologies, has pointed out the interests and significance of new modelling techniques and tools, which are particularly adapted to face two fundamental points: (i) the distribution of functional, decisional and informational capabilities of the enterprise leading to the characterisation of autonomous units and (ii) the development of co-operation policies between these units. This paper briefly presents the AOP3S framework, which aims to face some important aspects of these requirements. AOP3S is based on concepts mainly issued from a balanced approach embracing the Multi-Agent Systems and the CIMOSA architecture. An example is also provided.
\end{abstract}

\section{Keywords \\ Multi-agent System, CIMOSA, modelling}

The original version of this chapter was revised: The copyright line was incorrect. This has been corrected. The Erratum to this chapter is available at DOI: 10.1007/978-0-387-35390-6_58 


\section{INTRODUCTION}

The evolution of contemporary manufacturing systems can be analysed through an approach particularly appreciated in France, the Systemic Rationalisation (Hatchuel, 1992) (Terssac, 1992). It concerns the increase of manufacturing systems' performances throughout the adoption of pull methods of production (JT, Kanban), as well as the implantation of systems presenting higher levels of flexibility. Also, the Systemic Rationalisation puts accent on technological specialisation of the enterprises and, consequently, emphasises the formation of subcontracting networks. A good illustration of Systemic Rationalisation is the case of the French Aerospace company in which the performance was increased by the complete revision of their management system (henceforth based on management of interfaces between subcontractors), the compliance and homogenisation of data flow, and the implantation of a subcontractor network with more autonomy of the units (Pouget, 1992).

As far as our research is concerned, the Systemic Rationalisation helps to realise two important aspects concerning the modelling of manufacturing systems, which are involved in recent industrial challenges such as the extended enterprise (Browne, 1995), the virtual enterprise (Camarinha-Mattos, 1997), and the holonic manufacturing systems (Deen, 1993). These new approaches postulate, with more or less significance:

- The distribution of functional (competence, know-how), decisional and informational capabilities of the manufacturing systems leading to the characterisation of autonomous units and

- The development of co-operation policies (co-ordination and collaboration) between these units.

Consonant with these points and in order to improve the competitiveness of current enterprises, the CEN / TC310 / WG1 (Working Group of the European Committee for Standardisation, Technical Committee 310 - Advanced Manufacturing Technologies [CEN 94]) (Vernadat, 1994) has underlined the importance of new suitable techniques and tools to model manufacturing domains.

Our research observes such an assertion and proposes a framework, the Agent Oriented Programming Paradigm for Production Systems - AOP3S. This paper basically introduces AOP3S. Initially the notion of Distributed Manufacturing System - DMS - is presented. After, the main components of AOP3S are introduced focusing on aspects that show it as a balanced modelling approach. Following, an example illustrating the application of AOP3S is presented. Finally, some comments concerning the limits and perspectives associated to our research are granted.

\section{THE AGENT ORIENTED PROGRAMMING PARADIGM FOR PRODUCTION SYSTEMS (AOP3S)}

AOP3S is defined as a modelling paradigm able to generate and execute informatic models of Distributed Manufacturing Systems - DMS (Spinosa, 1996) (Spinosa, 1997a). It is issued from a cognitive approach, which means that AOP3S mainly 
deals with decision-making processes, and consequently the units' intelligence. AOP3S has three major components: the conceptual framework, the representation language and the representation methodology (see Figure 1). In the next paragraphs these main components, as well as, a more precise definition of DMS are presented.

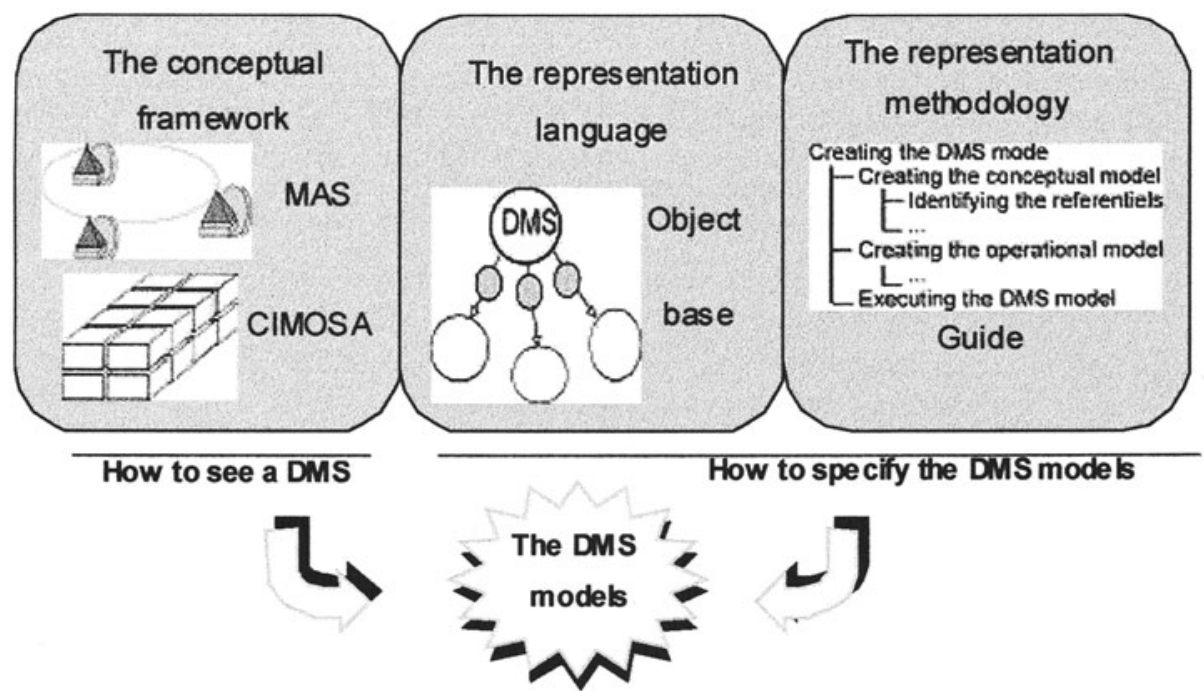

Figure 1 - The components of AOP3S.

\subsection{The notion of Distributed Manufacturing System (DMS)}

Briefly, a DMS is a manufacturing system that takes into account the distribution of functional, decisional and informational means into autonomous units as suggested by the Systemic Rationalisation. More precisely, the definition of DMS leads us to initially consider the ontology called DME (Distributed Manufacturing Enterprise), which meets a more global definition of the current manufacturing enterprises (Spinosa, 1997b). DME is a kind of dictionary containing formal descriptions of manufacturing and organisational entities permitting to define a terminology and, thus, facilitating the sharing and reusing of knowledge. Based on the DME ontology it is possible to settle that:

- A DMS is composed of a number of "units" aiming to accomplish manufacturing tasks in a "co-operative" way, as well as, a number of manufacturing resources that can be used in a shared way.

- An unit is an autonomous and intelligent actor able to decide, act, communicate and use manufacturing resources.

- Autonomy endows the "unit" with the capability to realise the manufacturing tasks by itself.

- Intelligence endows "unit" with the capability to decide face to different situations. It is noticed that the intelligence here is strictly defined from the 
operational viewpoint and not from the psychological or philosophical viewpoints.

To briefly illustrate the concept of DMS, an example is provided in a later section.

\subsection{The conceptual framework of AOP3S}

It represents the assertion "How to apprehend a DMS model". In a balanced way, it defines the theoretical aspects allowing to perceive DMS scenarios. Such aspects are mainly issued from CIMOSA architecture (CIMOSA, 1994) and Multi-Agent Systems - MAS (Ferber, 1996). As far as the former is concerned, the following points are considered:

- Rich reference. Mostly due to the consideration of an important number of case studies, CIMOSA possesses a very rich semantics strongly adapted to the modelling of industrial areas. AOP3S takes this semantics into account as a start point and introduces additional concepts related to Multi-Agent systems upcoming an improved semantics, which is more appropriated to the DMS modelling.

- Legacy systems. Presently, numerous enterprises having used CIMOSA for CIM implementation hold an important "knowledge" (models and know-how) to conduct their activities. AOP3S considers such enterprises are its main endusers. In this sense, the conceptual framework, leading to a more balanced process, induces a progressive approach allowing the adaptation of legacy models in order to facilitate the management of investments, as well as to acquire an adequate control of new technologies.

Regarding MAS concepts, they are particularly important due to their ability to represent knowledge. Some of the properties attributed to the MAS and took into account by AOP3S are:

- Processing of intelligence. Autonomy and cooperation aspects are the central points. Due to the use of precise methods and techniques to model the reasoning, AOP3S can deal with the units' intelligence, which is behind the understanding and control of several situations in which a DMS is faced with.

- Construction of models based on multi-reasoning. Several situations in a DMS conduct the units to realize decisional actions mobilizing different problem-solving methods that must performed together. Considering certain restrictions, AOP3S provides the units with a clean reasoning that allows the assimilation of these different methods.

- Modelling of complex systems. The complexity of production systems, notably characterised by the great amount of units as well as by the important number of their interactions, has been evoked for a long time. AOP3S facilitates the modelling of production systems by providing means to deal with a great number of actors, as well as means to consider the relationships among these actors. Note that, the need to provide such means is at the genesis of MAS. 
- Validation of models through simulation. The use of MAS can raise very powerful tools to analysis the behaviour of interactive elements. AOP3S makes intensively use of this MAS property and provides important means allowing the simulation, improvement and validation of DMS models.

\subsection{The representation language of AOP3S}

The representation language describes "How to define and specify a DMS model". It corresponds to an object base that allows the description of DMS model as postulated by the object-oriented approach. The base comprises two major object groups. A first group that represents a generic DMS conceived as being a generic MAS, from which specific DMS can be instantiated. A second group belonging to the CIMOSA architecture, more precisely the modelling framework of CIMOSA architecture. The last group supports several "actions" performed by the first one, as well as it represents the linking with legacy systems.

\subsection{The representation methodology of AOP3S}

Together with the representation language, the representation methodology upholds the assertion "How to define and specify a DMS model". It establishes phases and steps allowing to guide the utilisation of the conceptual framework and the representation language of AOP3S. Note that, the phases and steps of AOP3S strongly observe the integration with the phases and steps composing the CIMOSA methodology.

\section{EXAMPLE}

To illustrate the purposes of AOP3S, a real example concerning a DMS dedicated to the production of a helicopter's component is presented.

\subsection{Presentation of the case}

The main piece is called MainPart. The sequence of operations and the resources used in the fabrication of MainPart are showed Figure 2. 


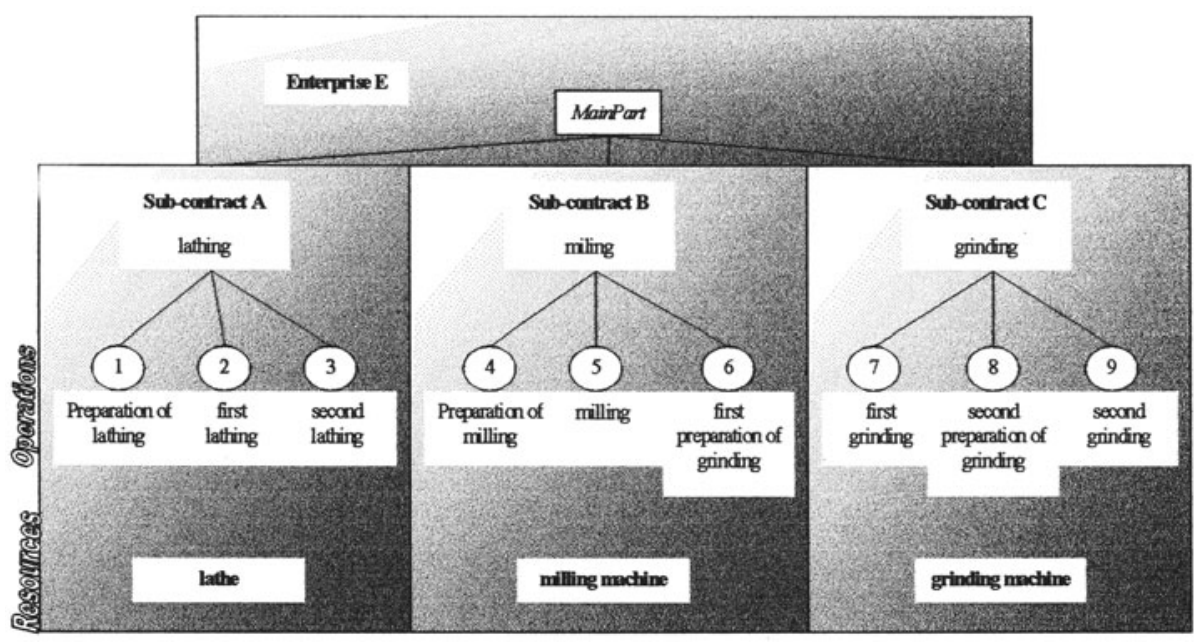

Figure 2 - Operations and ressources to manufacture MainPart.

Three enterprises are involved with the production of MainPart:

- A main enterprise, called $E$, which is responsible for the execution of grinding operations. To accomplish these operations, $E$ is composed of: (i) the unit Unit $_{\text {coord-E}}$, which is responsible by the co-ordination (assigning and supervision) of the tasks among the other units; (ii) the unit Unit CAD/CAM, which provides the projects of MainPart by means of CAD/CAM systems and adequate communication means, and (iii) the unit Unit ${ }_{\text {Grinding, }}$ that executes the grinding operations $6,7,8$ and 9 .

- A sub-contractor, called $A$, responsible for the accomplishment of lathing operations. $A$ is composed of: (i) the unit Unit coord-A, which receives the requests made by $E$, and co-ordinated the execution of the operations in $A$, and (ii) the unit Unit $t_{\text {lathing-A }}$ dedicated to realize the operations 1,2 and 3.

- A sub-contractor, called $B$, responsible for the accomplishment of milling operations. $B$ is composed of: (i) the unit Unit $t_{c o r d-B}$, which receives the requests made by $E$, as well as co-ordinated the execution of operations inside $B$, and (ii) the unit Unit milling-B $_{\text {B }}$ dedicated to execute the operations 4 and 5.

\subsection{Simulation of the case}

AOP3S can give rise to different kinds of implementations. Hereafter, the case is showed thanks to a prototype of implementation, which focuses on simulation aspects of DMS models. In this sense and intending to render more practical the simulation, it is assumed that the objective of the DMS model is the definition of a Decision Support System as suggested in (Spinosa, 1997a).

Initially, a conceptual model of the DMS is generated by an interactive way. The model contains components of the DME ontology, which identify the descriptive and behavioural aspects of the DMS. See Figure 3. Afterward and also through an 
interactive way, an operational model is generated according to the representation language of AOP3S. In other wors, this step "translates" the components of the conceptual model into objects. The whole set of these objects defines a multi-agent system that, in turn, represents the Decision Support System.

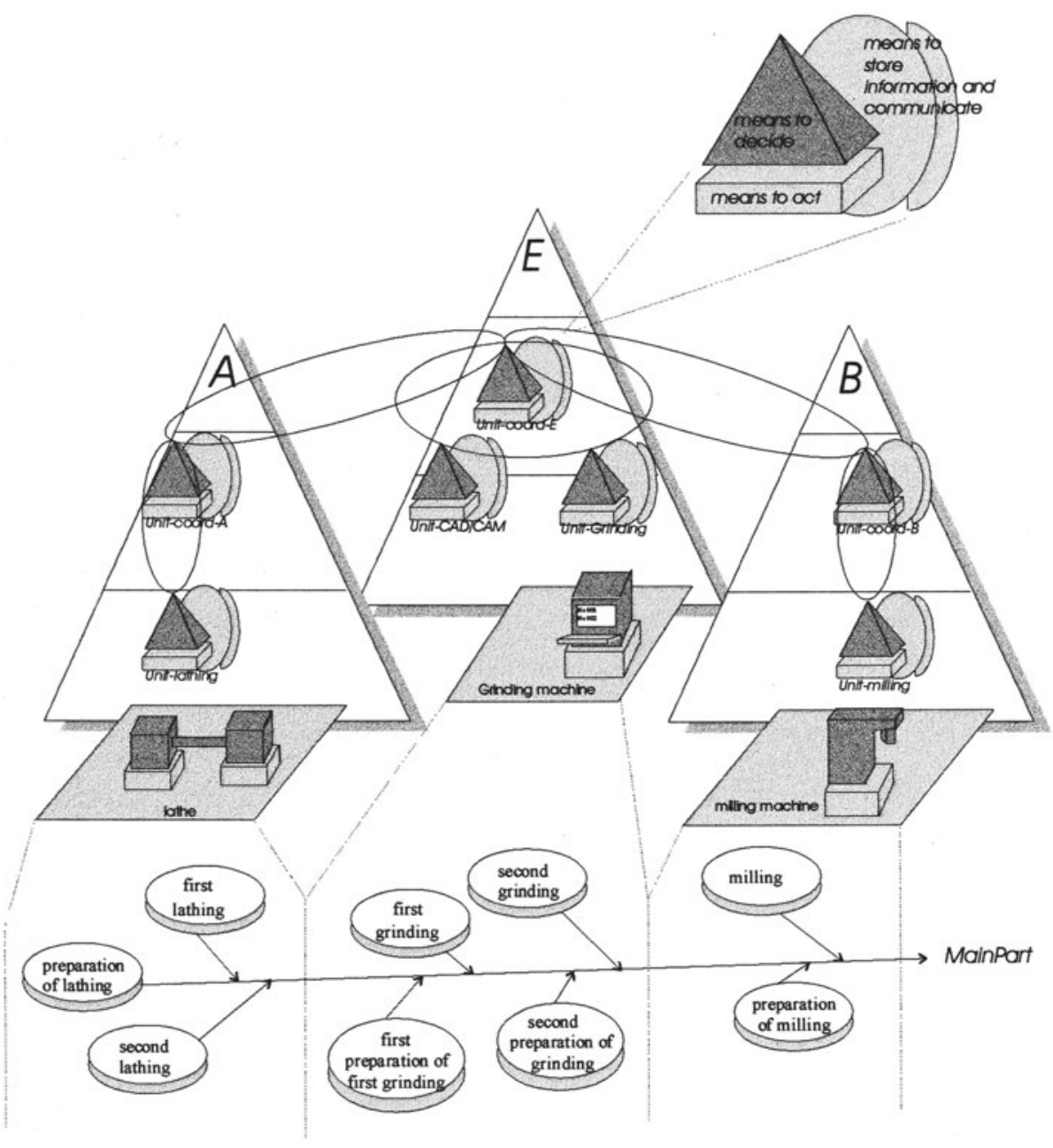

Figure 3 - Illustration of the DMS conceptual model.

Finally, the multi-agent system is executed allowing to verify the evolution of actions, which are associated to each manufacturing resource. Moreover, it is possible to follow-up the actions concerning the decision-making processes undertaken by the units (the agents) to co-ordinate in a co-operative way the efforts made by the units. The evolution of actions, as well as, the follow-up of the 
reasonning constitute the Decision Support System. Figure $4^{1}$ shows some results of the execution of the present case. A possible interpretation of the results could be as follows.
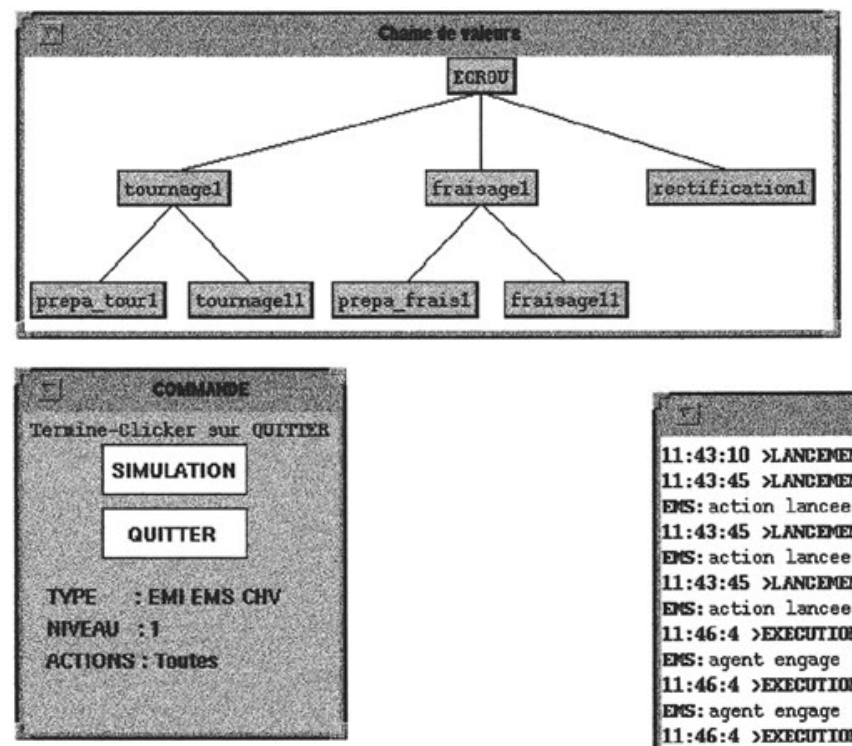

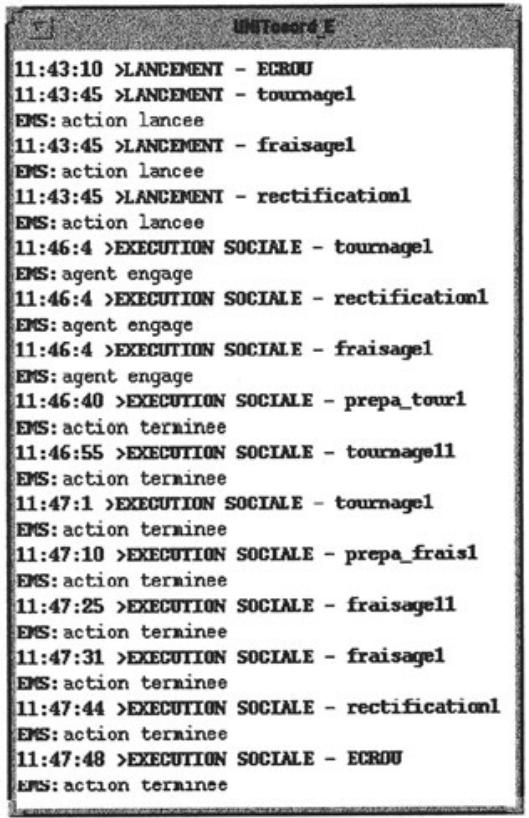

Figure 4 - Results of the simulation.

In the window Commande the user specifies some parameters to indicate the whole behaviour of the simulator, such as the observation level of the evolution of the reasoning, which, in the present case, has been assigned as EMS to only indicate the follow-up of the reasoning of the main co-ordinator. The window Chaine de Valeurs shows a diagram representing the evolution of milling, lathing and

${ }^{1}$ Considering that the original system has been developed to validade AOP3S in the context of a French Aerospace problem, the language used in the interfaces is French. 
grinding operations to produce MainPart in a co-operative way. The reasoning evolution is presented in the window UNITcoord-E and can be defined as being the execution of a co-operation protocol, which carries out a negociation process among the different co-ordinators. Initially, UNITcoord-E makes requests to the sub-contractors' co-ordinators to accept the assignement of tasks. The lines beginning with the word Lancement in the window UNITcoord-E represent such requests. The sub-contractors' co-ordinators can accept or refuse the tasks. The lines with the sentence agent engage in the window UNITcoord-E indicate that each co-ordinators has accepted its task. Once the tasks performed, the main coordinator is informed. The sentence action termine in the window UNITcoord-E indicates this status.

\section{CONCLUSION}

This paper introduces a modelling paradigm called AOP3S, which provides new modelling concepts and tools taking into account two important points of the current manufacturing systems: the distribution of functional, informational, and decisional capabilities of the enterprise leading to the characterization of autonomous units and (ii) the development of cooperation policies (coordination and collaboration) between these units.

AOP3S lies in giving rise and triggering further research towards the development of adequate modelling techniquesof manufacturing systems. It fits together methods issued from CIMOSA architecture and Multi-agent Systems. As far as CIMOSA is concerned, AOP3S takes into account its rich semantics to model industrial areas, as well as, its already acquired know-how to deal with legacy systems. Concerning the Multi-agent Systems, AOP3S gets several of their properties such as the ability to process the intelligence and the multi-reasoning. All these considerations conduct to a more balanced introduction of important concepts such as those postulated by the virtual enterprise, extended enterprise and holonic manufacturing systems.

\section{ACKNOWLEDGEMENT}

We thank CNPq (R \& D Brazilian Council) to the financial support given to realize the almost totality of this work. Also, we thank the DIAM for the orientation and the allocation of necessary resources.

\section{REFERENCES}

Benbow, C.P. and Stanley, J.C. (1980) Sex differences in mathematical ability: fact or artifact. Science, 210, 1262-4.

Browne J., (1995) The Extend Enterprise: Manufacturing and The Value Chain", IEEE/ECLA/IFIP International Conference on Architectures and Design Methods for Balanced Automation Systems, Chapman\&Hall., pp.5-16. 
Camarinha-Matos, L. Afsarmanesh, H., Garita, C., (1997) Towards an Architecture to Virtual Enterprises. Proc. Of the $2^{\text {nd }}$ World Congress on Intelligent Manufacturing Processes \& Systems, Budapest, Hungary, June 10-13.

CIMOSA, (1994) CIMOSA : Open System Architecture for CIM - technical base line. CIMOSA Association (E.V.) version 3.0.

Deen S.M., (1993) Cooperation Issues in Holonic Manufacturing Systems. Information Infrastructure Systems for Manufacturing (B-14), Yoshikawa $\mathrm{H}$. and Goossenaerts J. (Eds.), Elsevier Science B.V., (North Holland).

Ferber J., (1996) Les systèmes multi-agents. Vers une intelligence collective. InterEditions, Paris.

Hatchuel A., Sardas J.C., (1992) Les grandes transitions contemporaines des systèmes de production, une démarche typologique. Les Nouvelles Rationalisations de la Production, Cépaduès-Editions, Juillet, pp. 1-24.

Pouget M., Allard F., (1992) Rationalisation systémique et gestion de production: le cas de l'Aérospatiale - Division Avions. Les Nouvelles Rationalisations de la Production, Cépaduès-Editions, Juillet, pp. 63-86.

Spinosa, L. M., Espinasse, B., Chouraqui, E. (1997a) For a Decision Support System to Distributed Manufacturing Systems : A Multi-Agent and CIMOSA Based Approaches. IFAC/IFIP Conference on Management and Control of Production and Logistics, august 31 - september 3, Campinas, Brazil.

Spinosa, L. M., Espinasse, B., Chouraqui, E., (1997b) Distributed Manufacturing Enterprise Modeling : the DME framework, towards an ontological approach. ICEIMT'97 Conference, 28-30 octobre, Turin, Italie.

Spinosa, L. M, (1996) Contribution à la modélisation d'entreprises manufacturières distribuées fondée sur une approche multi-agents, Thèse de Doctorat, Université d'Aix-Marseille, 7 octobre.

Terssac, G., Dubois, P. (1992) Les rationalisations: quels choix pour quelles conséquences. Les Nouvelles Rationalisations de la Production, CépaduèsEditions, Juillet, pp. XVII-XXXV.

Vernadat, F., (1994) Future R\&D Directions for CIM Deployment. European Workshop on Integrated Manufacuring Systems Engineering, Grenoble, France, pp. 3-6. 